\title{
Redescription of megalopa and juvenile development of Pachygrapsus gracilis (Decapoda: Grapsidae) from the Amazon region, reared in the laboratory
}

\author{
Danielle C. B. Arruda' \& Fernando A. Abrunhosa ${ }^{1,2}$ \\ ${ }^{1}$ Laboratório de Carcinologia, Instituto de Estudos Costeiros, Universidade Federal do Pará. Campus Universitário de Bragança, \\ Alameda Leandro Ribeiro, Aldeia, 68600-000 Bragança, PA, Brazil, E-mail: danicbarruda@yahoo.com.br; faraujo@ufpa.br \\ ${ }^{2}$ Corresponding author.
}

\begin{abstract}
This present study re-describes the megalopa stage and provides detailed morphological descriptions and main growth changes observed in stages I through VII of the juvenile instars of the dark shore crab Pachygrapsus gracilis (Saussure, 1858), from the Amazon region. The specimens in this study were reared in the laboratory and the megalopae were collected at Ajuruteua beach in northeastern Pará, Brazil. Previous studies had described the megalopa of $P$. gracilis from Mexican waters, as well as those of Pachygrapsus transversus (Gibbes, 1850) and Pachygrapsus marmoratus (Fabricius, 1787). A comparison between the Mexican and Amazonian populations of $P$. gracilis revealed significant morphological differences. The main difference is the presence of 3 elongated setae on the $5^{\text {th }}$ pereiopods of individuals of the Amazonian population. The setal number and their arrangement in the appendages also differed. In P. gracilis, the male and female genital openings are observed from the juvenile instar III, whereas differentiation in male pleopods is observed only in juvenile instar V. In females, the pleopods undergo rapid differentiation during juvenile instar VI. These morphological comparisons and other observations on development are briefly compared and discussed with reports for other species.

KEY WORDS. Description; growth; morphology; transitory stage.
\end{abstract}

The dark shore crab Pachygrapsus gracilis (Saussure, 1858) has a wide distribution, occurring in the western Atlantic from the Caribbean to Texas, French Guiana, Brazil (Trinidad and from Ceará to Rio Grande do Sul) and Argentina, In the eastern Atlantic the species occurs from Senegal to Angola (Melo 1996, Poupin et al. 2005).

Pachygrapsus Randall, 1839 megalopae was described in the past from individuals collected in the natural environment: P. marmoratus (Fabricius, 1787) by Guerao et al. (1997), P. transversus (Gibbes, 1850) by Flores et al. (1998) and P. gracilis by Chárazo-Olvera \& Rocha-Ramírez (2007). These studies used specimens collected from the environment, probably due to the difficulty of obtaining the stage of megalopae under laboratory conditions. Only two studies on the juvenile growth and morphology of this group are available in the scientific literature: Guerao et al. (1997) for P. marmoratus and Flores et al. (1998) for P. transversus.

GUERAO et al. (1997) described the morphology of the carapace, pereiopods and third maxillipeds of the juvenile instar I of $P$. marmoratus. Their data provide information on the size of the carapace up to the juvenile IV. Flores et al. (1998) described in detail the megalopa, the first crab instar, and the juvenile development instars of $P$. transversus giving emphasis on the process of pleopod differentiation up until juvenile instar VII.
Studies on crab growth are important because some morphological characteristics, including secondary sexual characters, which arise at the juvenile phase, are useful in the identification of species, as well as age and sex determinations.

The morphological characteristics found in crustaceans have contributed significantly to the understanding of the taxonomic, systematic and phylogenetic nature of crustaceans. They have also generated information which has helped the understanding of their biology and assisted population management (BARUTOT et al. 2001). However, morphological descriptions of crustaceans must be accurate, and describe the setal arrangement, the number of the juvenile appendages and other structures correctly.

In some cases, intraspecific variation has been found in individuals of different populations. Nelice M. Batistelli (unpubl. data), for example, found discrepancies in setal number and setation arrangements in re-descriptions of various fiddler crab larvae. More studies on the morphological stages and new descriptions of larval and juvenile stages of crustaceans are necessary in order to clarify these differences.

Due to the scarcity of studies detailing the morphological development of crustaceans and the growth of these animals, it is necessary to conduct further studies on the growth and morphology of juvenile instars. The present study re-de- 
scribes the megalopa stage of $P$. gracilis inhabiting the Amazon region, and describes important morphological changes observed during the growth from juvenile instars I to VII, of.

\section{MATERIAL AND METHODS}

In February 2008, 116 megalopa were obtained at Ajuruteua $\left(00^{\circ} 49^{\prime} 20.2^{\prime \prime} \mathrm{S}, 46^{\circ} 36^{\prime} 02.2^{\prime \prime} \mathrm{W}\right)$ Beach, municipality of Bragança (northeastern Pará state, Brazil). The specimens were collected off of mangrove leaves, pieces of trunks and roots brought by the tide. They were identified in the laboratory when they reached the juvenile instar. Specimen identification followed Rodriguez (1980), Melo (1996) and Poupin et al. (2005).

In the laboratory, specimens were placed individually in plastic recipients with sea water (salinity 30 ) and a small rock shelter. The temperature was maintained at $26.5 \pm 1.14^{\circ} \mathrm{C}$, photoperiod regime (12:12 h/light:dark cycle) and $\mathrm{pH} 8.1$. Every two days the water of the recipients was changed. The individuals were fed live Artemia nauplii daily and were monitored twice a day. The exuviae and dead animals were preserved in glycerol+ethylic alcohol 70\% (1:1) solution.

At least 10 specimens of each stage were dissected with fine needles (BD Ultra-Fine ${ }^{\circledR}, 12.7$ X $0.33 \mathrm{~mm}$ ) under an optical Zeiss (Axioskop 40) microscope equipped with an ocular micrometric. The appendages were extracted and transferred to another slide where they were stained with a solution of methylene blue 1\% (sometimes was used). The terminology used in the descriptions follows Pohle \& Telford (1981), Guerao et al. (1997), Flores et al. (1998), Garm (2004), and ChÁrazoOlvera \& Rocha Ramírez (2007). The studied specimens were deposited at the crustacean collection of Museu Paraense Emílio Goeldi, under the catalog number MPEG-817.

The individuals were reared until juvenile instar VII. During rearing, data on survival and intermolt periods were obtained for individuals in each juvenile instar. The carapace width (CW) was considered as an independent variable or as a reference (in axis $\mathrm{x}$ ) because of its greater amplitude and because it is the best representative dimension of organism size (HARTNOLL 1982). This variable was used for calculating the percentage of molt increment and absolute increment after each ecdise. The abdomen width of male and female specimens was obtained by measuring the $4^{\text {th }}$ abdominal somite.

The percentage of molt increment (\%MI) was estimated by the following formula: $\% \mathrm{MI}=\left[\left(\mathrm{CW}_{2}-\mathrm{CW}_{1}\right) \times 100\right] / \mathrm{CW}_{1}$; where $\mathrm{CW}_{1}$ and $\mathrm{CW}_{2}$ are pre-molt and post-molt sizes, respectively.

The absolute increment (AI) after each ecdise was obtained using the following equation: $\mathrm{AI}=\mathrm{CW}_{2}-\mathrm{CW}_{1}$; where $\mathrm{CW}_{1}$ is the carapace width in pre-molt and $\mathrm{CW}_{2}$ the carapace width in post-molt.

The morphometric relationship between the carapace length (CL) and carapace width (CW) throughout the juvenile development was obtained by linear regression.

\section{RESULTS}

\section{Megalopa}

A total of 89 megalopae molted into the juvenile instar I. The remaining individuals died during the experiment. These were preserved. The first molting was recorded on the second day, and the last on the $18^{\text {th }}$ day of culture after collections in the field (Fig. 1). Large frequencies of metamorphosed megalopae were recorded on the third and fourth days of rearing. The mean intermolt period was $5.72 \pm 4.45$ days.

\section{JUVENILE GROWTH}

During the culture, the mortality of juveniles was quite low: only three specimens died in the juvenile instars I, II and III, respectively. The mean intermolt period gradually increased during the juvenile development and after consecutive molts (Fig. 2). In juvenile instar I, the intermolt period mean was $6 \pm 3$ days whereas in the juvenile instar VII it averaged $20 \pm 12$ days.

The carapace length of the juvenile instar I $(1.96 \pm 0.07$ $\mathrm{mm})$ was similar to that found for megalopa $(1.97 \pm 0.04 \mathrm{~mm})$. The growth (carapace width) of each subsequent juvenile instar showed an increase during the days of culture and molts (Fig. 3). In the juvenile instar I, the mean carapace width was $2.21 \mathrm{~mm}$ and in the juvenile instar VII the mean carapace width was $7.42 \mathrm{~mm}$. The carapace width of male and female crabs was similar during juvenile growth until the VII instar (Fig. 4).

The percentage of molt increment showed a reduction at each molt event (Fig. 5). From the juvenile instar I to juvenile instar II, the mean rate of increment was $31.13 \pm 8.75 \%$, whereas from the juvenile instar VI to VII it was $18.51 \pm 4.16 \%$. The absolute molt increment increased at each molt event; from juvenile instar I to II the mean was $0.68 \mathrm{~mm}$ and from the juvenile instar VI to VII the mean was $1.17 \mathrm{~mm}$ (Fig. 5).

The width of the abdomen in juvenile forms increased during juvenile growth (Fig. 6). However, the width of the abdomen of males and females presented differences only in the juvenile instars VI and VII (Fig. 6). In the juvenile instar I, the mean abdomen width in males and females was similar, $0.70 \pm$ $0.04 \mathrm{~mm}$ and $0.60 \pm 0.04 \mathrm{~mm}$, respectively. In juvenile instars VI and VII, these values were very different for both sexes; females had $2.10 \pm 0.4 \mathrm{~mm}$ and $3.20 \pm 0.76 \mathrm{~mm}$ of abdomen width, while males presented $1.70 \pm 0.19 \mathrm{~mm}$ and $2.10 \pm 0.15 \mathrm{~mm}$, respectively.

\section{MORPHOLOGICAL DESCRIPTION}

\section{Megalopa}

Carapace (Fig. 7): length: $1.97 \pm 0.04 \mathrm{~mm}$; width: $1.39 \pm$ $0.04 \mathrm{~mm}$; subretangular; surface showing four distinct lobes on the anterior portion and few small setae; middle and posterior portions fringed with numerous small marginal setae; anterolateral region showing a small enlargement; rostrum elongated, triangular and strongly deflected ventrally (Fig. 8); eyes large, ocular peduncle well-developed; the presence of the dorsal organ was not detected. 

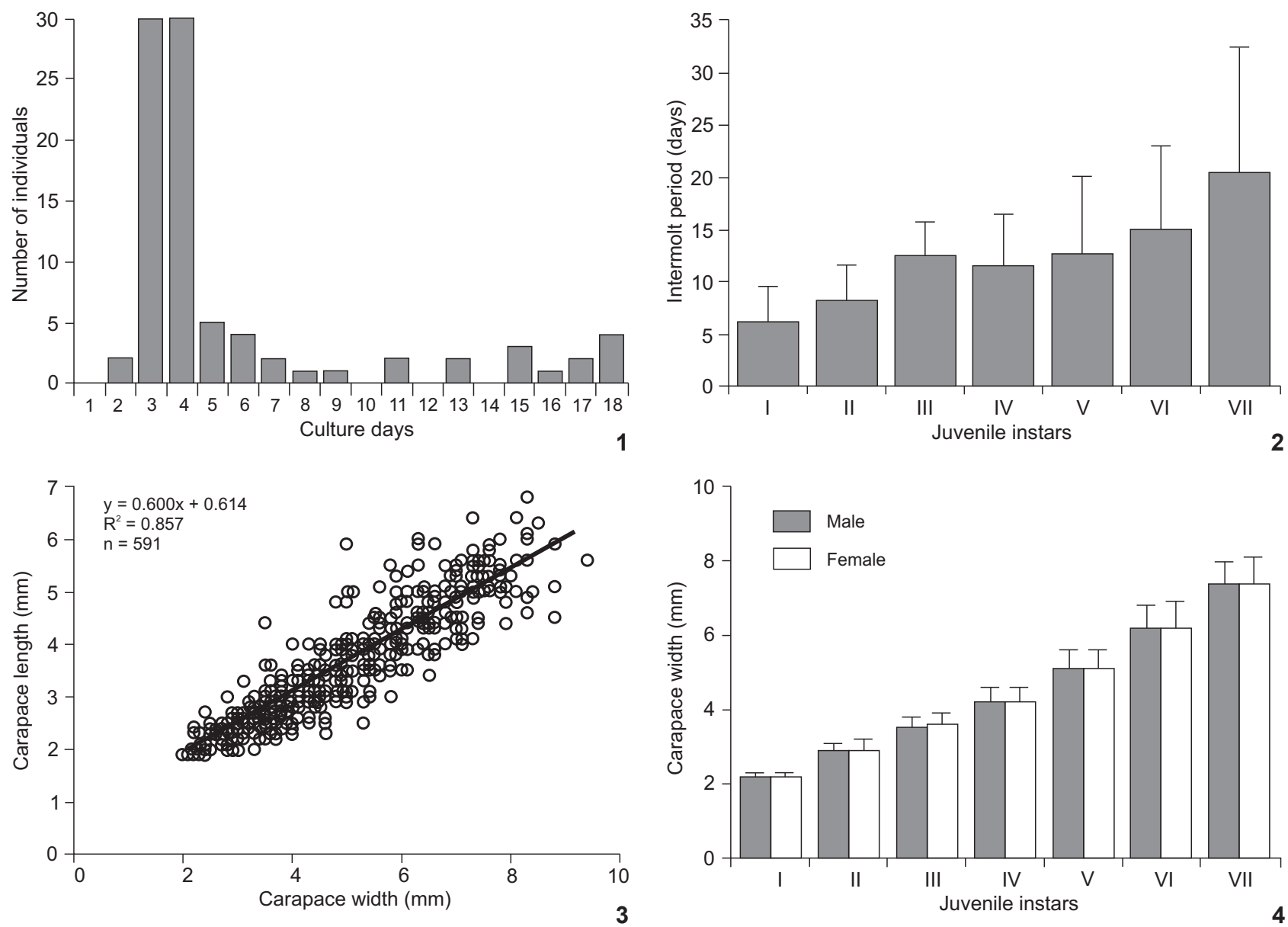

Figures 1-4. Pachygrapsus gracilis: (1) intermolt period of the megalopa stage; (2) mean of intermolt period (days) of each juvenile instar; (3) carapace width and carapace length at each juvenile instar; (4) mean carapace width of males and females at each juvenile instar.
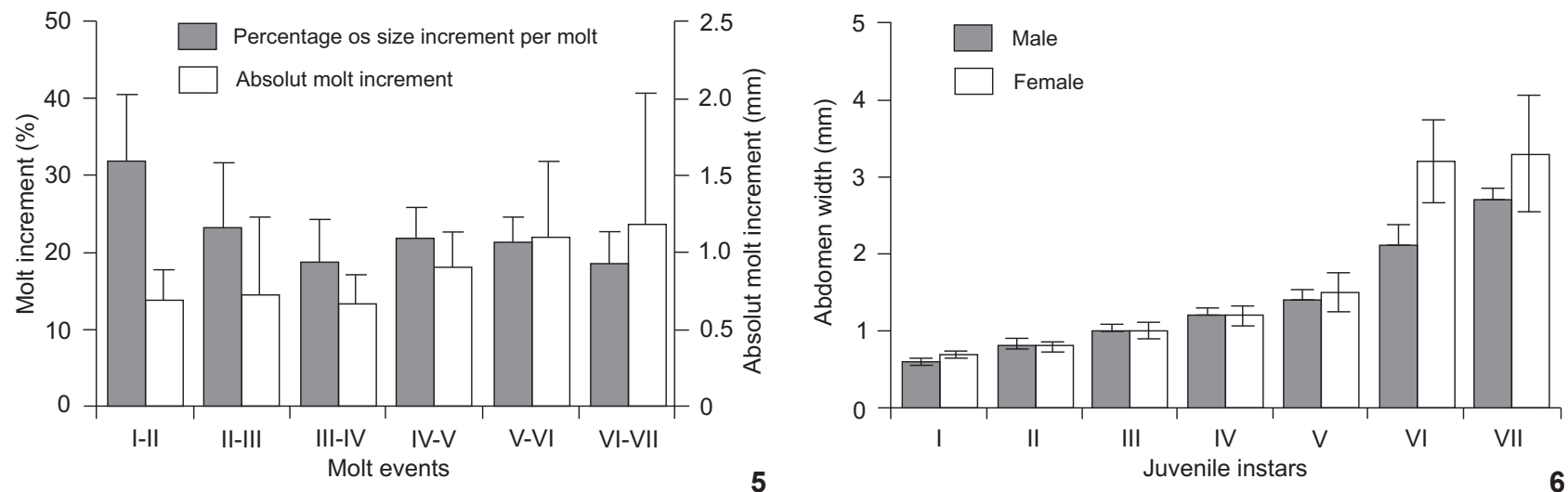

Figures 5-6. Pachygrapsus gracilis: (5) mean percentage of molt increment and mean absolute molt increment for each juvenile instar; (6) mean abdomen width of males and females in each juvenile instar. 
Antennule (Fig. 11): peduncle 3-segmented with 3, 5, 2+1 simple setae; endopod unsegmented with $2+1$ simple setae; exopod 5-segmented with $0,0,2,0,1+3$ simple setae and 0,8 , 4, 4,0 aesthetascs.

Antenna (Fig. 12) - 11-segmented with 0, 1+1, 2, 0, 0, 4, $2,4,0,3,3$ simple setae; no sign of statocyst cavity in the basipod.

Mandible (Fig. 13): uncalcified, symmetrical with bladelike margin, incisive and molar processes indistinguishable; mandibular palp 3-segmented with 10 setae on distal segment, some setae are evidently pappose and some appear to be plumodenticulate but such pattern of setules is not obvious.

Maxillule (Fig. 14): coxal endite with seven terminal and three subterminal plumodenticulate setae and nine scattered simple setae; basial endite with 12 terminal cuspidate setae, 10 subterminal plumodenticulate setae, but the setules are minute and almost imperceptible, and 4 proximal simple setae; endopod 2-segmented, lacking setae.

Maxilla (Fig. 15): coxal endite bilobed, proximal lobe with five terminal simple setae and nine subterminal plumose setae; distal lobe with two terminal and four subterminal simple setae; basial endite bilobed, proximal lobe with 8-9 terminal simple setae, one terminal plumose setae and one subterminal simple setae; distal lobe with 9-12 terminal simple setae and one subterminal simple setae; endopod unsegmented, lacking setae; scaphognathite with approximately 70-72 marginal plumose setae and 3-4 simple setae on the lateral surface.

First maxilliped (Fig. 16): coxal endite with four terminal simple setae, one terminal plumose setae and 12 subterminal simple setae; basal endite with 13 terminal simple setae and two subterminal simple setae; endopod unsegmented with two distal simple setae; exopod 2-segmented with three simple setae on proximal and four terminal plumose setae on distal segment; well development epipod with 10 long simple setae.

Second maxilliped (Fig. 17): coxa and basis fused; endopod 5-segmented with 0, 1 long, 1, 6 simple setae, $5^{\text {th }}$ segment with 11 terminal and four subterminal denticulate setae; exopod 2-segmented with two simple setae on proximal segment and five terminal plumose setae on distal segment; epipod with five long simple setae.

Third maxilliped (Fig. 18): coxa and basis fused bearing nine simple setae; endopod 5-segmented ischium, merus and carpus with $13+1,5+4,5$ simple setae, propodus and dactyl bearing 9 and 8-10 strong denticulate setae; exopod 2-segmented with five minute lateral simple setae on proximal segment and four terminal plumose setae on distal segment; well developed epipod with 34-36 long simple setae.

Pereiopods (Fig. 7): well-developed with few setae distributed on the segments (as illustrated); P1 - Chelipods similar in shape and size; dactyl lacking teeth; propodus showing two truncated teeth on the posteroventral margin, propodus with one strong ventral spine close to dactyl (Fig. 9); P2-P4 Dactyl ventrally curved with acute extremity, showing strong teeth on the ventral margin; P5 - Dactyl with three long denticulate setae and a strong terminal spine, ventral margin lacking teeth (Fig. 10).

Abdomen (Fig. 7): 6-segmented; $2^{\text {nd }}, 3^{\text {rd }}, 4^{\text {th }}$ and $5^{\text {th }}$ segments with two small setae on the posterior surface; telson semi-oval-shaped with two long setae and 4-6 small setae.

Pleopods (Fig. 19): well-developed; endopods bearing four cincinulli; exopod from pl 1 to pl 4 with 28, 23, 24, 22, plumose natatory setae, respectively.

Uropods (Fig. 19): endopod absent; exopod 2-segmented with three plumose setae on proximal segment and 15-16 plumose setae on the distal segment.

\section{Juvenile I}

Carapace (Fig. 20): length: $1.96 \pm 0.07 \mathrm{~mm}$; width: 2.20 $\pm 0.13 \mathrm{~mm}$; markedly striated on metabranchial and mesobranchial regions; mesogastric, metagastric, cardiac and intestinal regions smooth; orbital extern tooth and antero-lateral tooth presents, the latter is smallest; frontal, orbital and lateral depressions visible; gastric, cardiac and branchial regions already distinct; eyes relatively large when compared to adult.

Antennule (Fig. 21): peduncle 3-segmented, proximal segment (bulb) with minutes plumose setae arranged in transverse rows, $2^{\text {nd }}$ segment with one terminal and four subterminal simple setae, $3^{\text {rd }}$ segment with $4+1$ simple setae; endopod 3 -segmented with 1, 2, 1+2 simple setae; exopod 6-segmented with $0,10-12,11,3,0,0$ aesthetascs and $0,2,2,1,3+1$ long, two simple setae.

Antenna (Fig. 22): peduncle 3-segmented with 5+3, 0, 0 plumose setae and 0, 6, 0 simple setae; flagellum 8-segmented with $0,4,2,2,4,0,2,2$ simple setae; no sign of statocyst cavity in the basipod.

Mandible (Fig. 23): calcified, asymmetrical, left mandible with blade-like margin, incisive and molar processes indistinguishable, mandibular palp 3-segmented with four and 14 plumose setae on $2^{\text {nd }}$ and $3^{\text {rd }}$ segments; right mandible incise process showing two blunt teeth and blade-like molar process, mandibular palp 3-segmented with six and 16 plumose setae on $2^{\text {nd }}$ and $3^{\text {rd }}$ segments.

Maxillule (Fig. 24): coxal endite with five terminal plumodenticulate setae and 28-30 simple setae arranged in all surface; basial endite with 15 terminal cuspidate setae, one pappose seta on lateral margin and 13 subterminal simple setae; endopod 2 -segmented with two plumose setae on proximal segment and $2+2$ plumose setae on distal segment.

Maxilla (Fig. 25): coxal endite bilobed, proximal lobe with 16 terminal and three subterminal plumose setae, distal lobe with five terminal plumose setae; basial endite bilobed, proximal lobe with 11 terminal and eight subterminal plumose setae; distal lobe with 14-15 terminal and three subterminal plumose setae and three subterminal simple setae; endopod unsegmented with one medial simple seta; scaphognathite with approximately 87-95 marginal plumose setae and 25 simple setae on the lateral surface. 


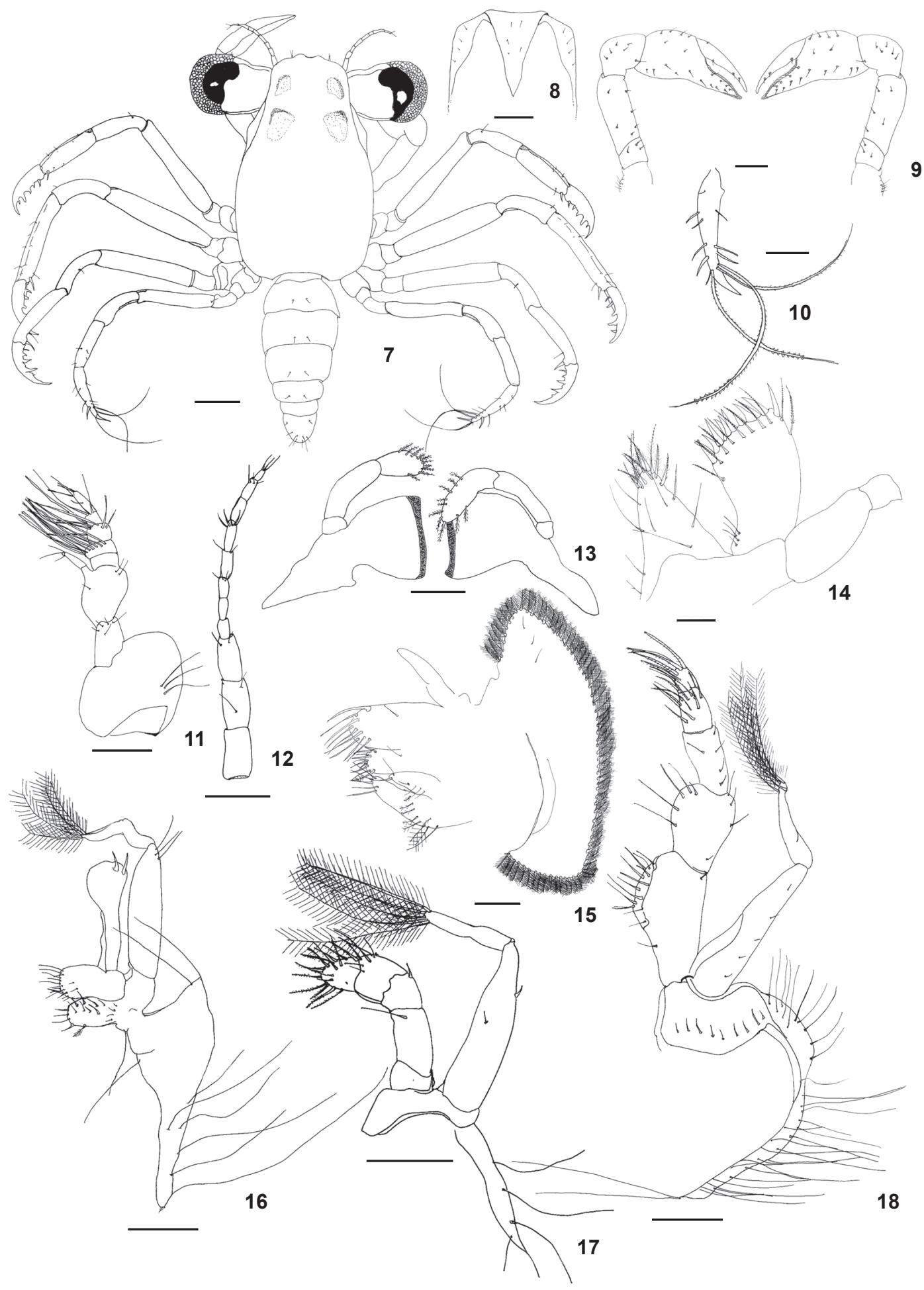

Figures 7-18. Pachygrapsus gracilis, megalopa appendages: (7) dorsal view; (8) ventral view of carapace showing detail of rostrum; (9) quelipods; (10) dactyl of pereiopod 5; (10) antennule; (10) antenna; (11) mandible (12) maxillule; (13) maxilla; (14) $1^{\text {st }}$ maxilliped; (15) $2^{\text {nd }}$ maxilliped; (16) $3^{\text {rd }}$ maxilliped. Scale bars: $7=0.02 \mathrm{~mm} ; 8-11,15-18=0.01 \mathrm{~mm} ; 13=0.006 \mathrm{~mm} ; 14=0.08 \mathrm{~mm}$. 


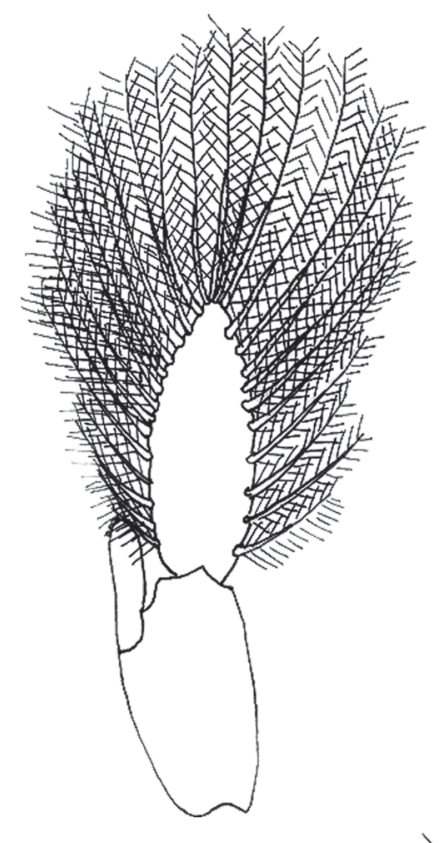

$\mathrm{PI} 2$
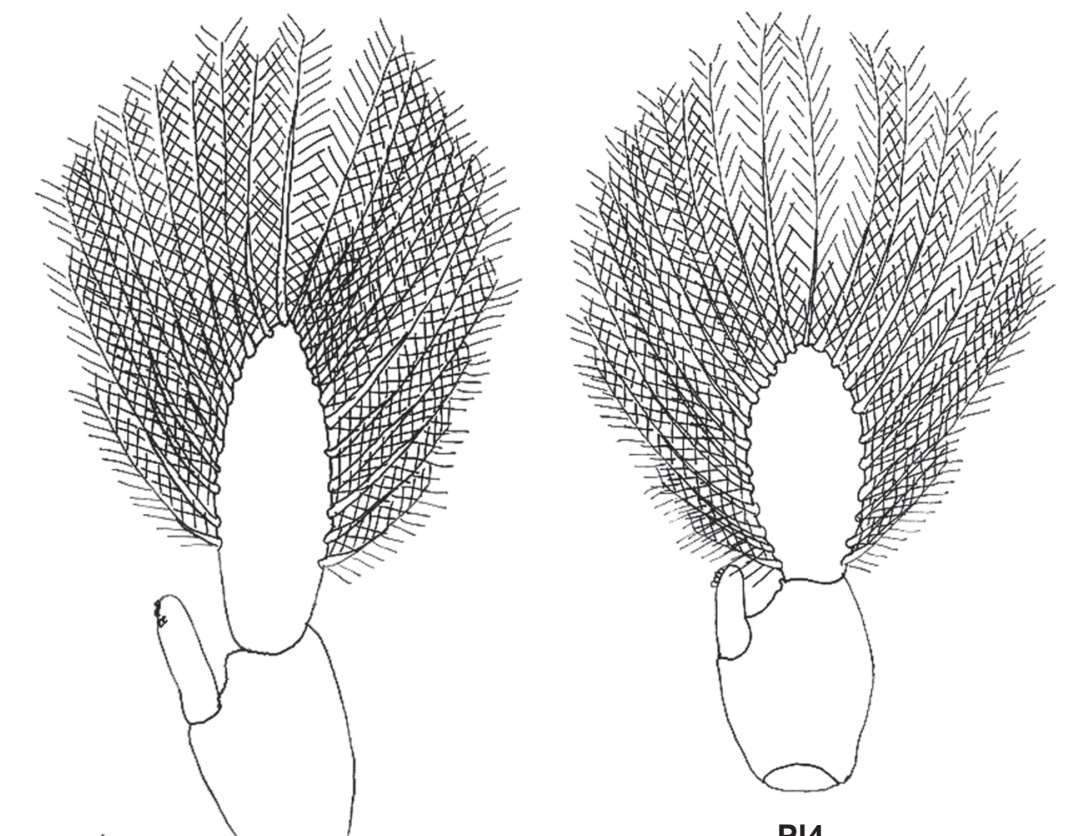

PI4

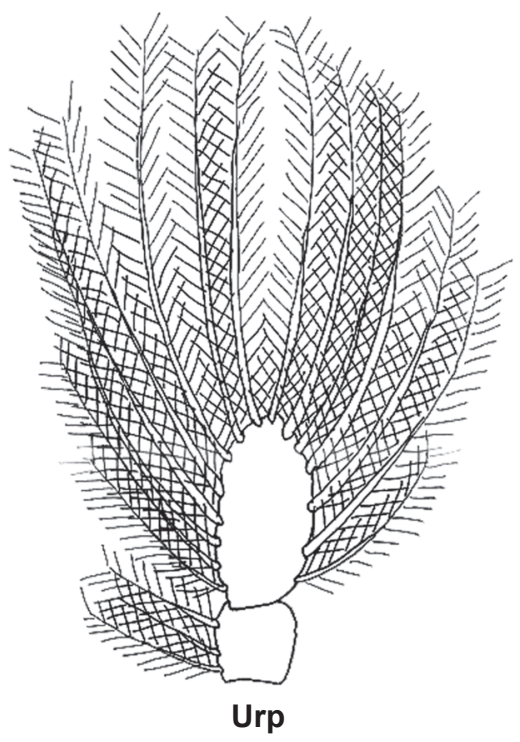

Figure 19. Pachygrapsus gracilis, megalopa. Pleopods (PI2-PI5) and uropod (Urp). Scale bar: $0.01 \mathrm{~mm}$.

First maxilliped (Fig. 26): coxal and basal endites almost entirely covered by plumose and simple setae, respectively; endopod 2-segmented, proximal segment with 12 small plumose setae on the margin, distal segment divided in two surfaces, dorsal surface with 12 and ventral surface with 9-13 plumose setae; exopod 2-segmented, proximal segment with 10 plumose setae, distal segment with four terminal plumose setae; well development epipod with 28 simple setae.

Second maxilliped (Fig. 27): coxa and basis fused with 3 plumose setae; endopod 6-segmented with 4, 6, 5+5+6, 5, 3+5 plumose setae, $6^{\text {th }}$ segment bearing seven plumose and $15-17$ plumodenticulate setae; exopod 2-segmented, proximal segment with a row of 12-13 dorsal plumose setae and 11-13 plumose setae on the outer margin, distal segment with 4 terminal plumose setae; well development epipod with 30 long simple setae. Third maxilliped (Fig. 28): coxa with 14 simple setae; basis with five plumose setae, endopod 5-segmented, ischium and merus with 38 and 20 plumose setae, carpus and propodus seg- 


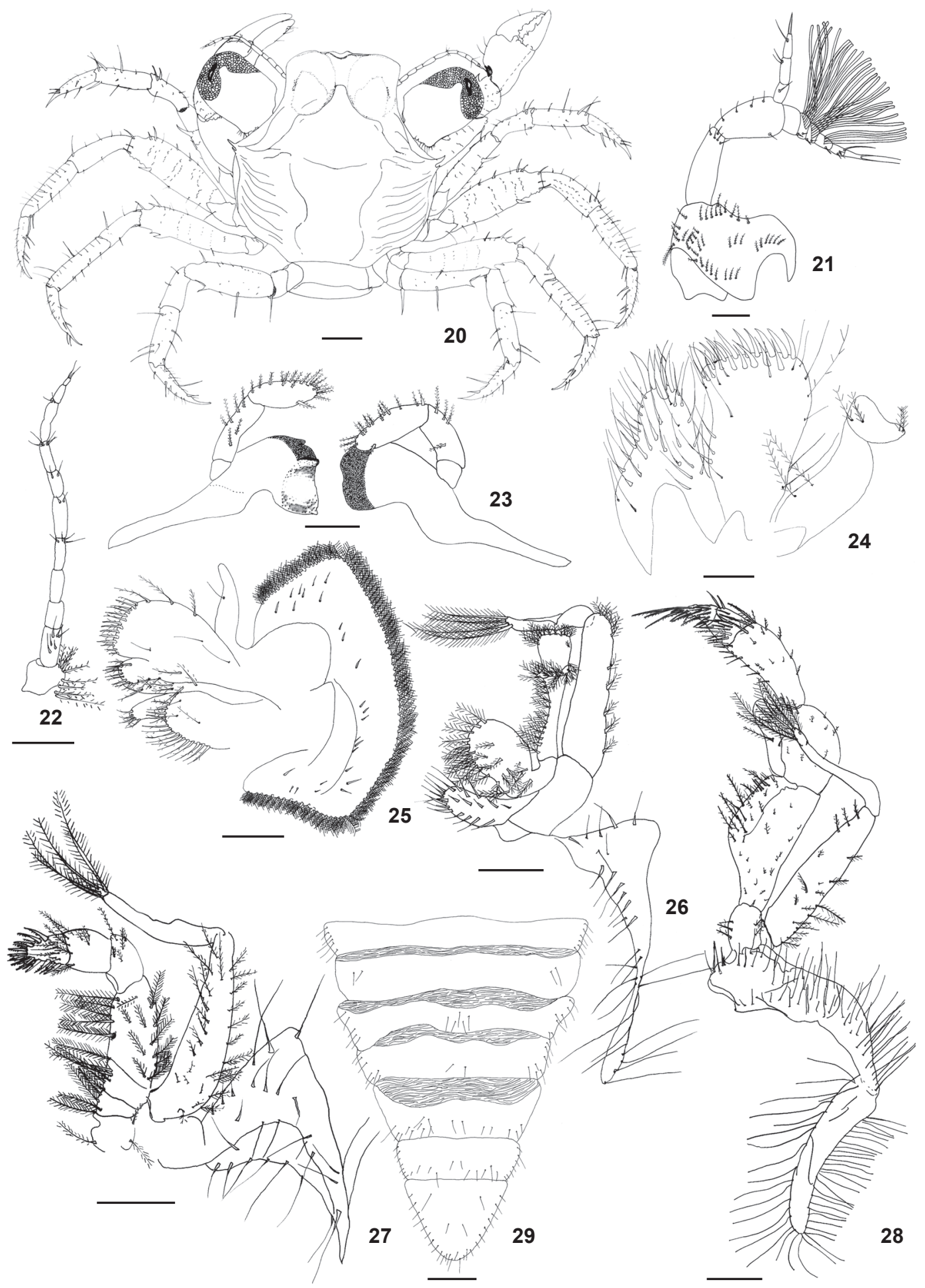

Figures 20-29. Pachygrapsus gracilis, juvenile I appendages: (20) dorsal view; (21) antennule; (22) antenna; (23) mandible; (24) maxillule; (25) maxilla; (26) $1^{\text {st }}$ maxilliped; (27) $2^{\text {nd }}$ maxilliped; (28) $3^{\text {rd }}$ maxilliped; (29) abdomen. Scale bars: $20,26=0.02 \mathrm{~mm} ; 21,23,25=$ $0.006 \mathrm{~mm} ; 22,27-29=0.01 \mathrm{~mm} ; 24=0.08 \mathrm{~mm}$. 
ments with 20 and 18 plumodenticulate setae, dactyl segment with 18 denticulate setae; exopod 2-segmented, proximal segment with 18 plumose setae, distal segment with five terminal plumose setae; well development epipod with approximately 105 long simple setae.

Pereiopods (Fig. 20): chelipods morphologically similar in shape and size, carpal tooth and laminar expansion denticulate of the merus already present as in adult form; pereiopods 2-5 with striated margins, showing numerous setae and spines distributed along the segments (as illustrated).

Abdomen (Fig. 29): $2^{\text {nd }}$ to $5^{\text {th }}$ somites with characteristic transverse striate; telson, a triangular in shape, bordered with 25 simple setae and four dorsal simple setae.

Pleopods: were not observed in this stage. Uropods absent (not observed in all juveniles stages).

\section{Development of other juvenile instars}

The main morphological changes were observed in the developmental sexual dimorphism in which they are described as follow. No significant morphological changes were observed in the carapace of subsequently juvenile instars (Fig. 30).

Juvenile II. Females: showing four pairs of pleopods $\left(2^{\text {nd }}\right.$ to $\left.5^{\text {th }}\right)$, each one biramous and rudimentary, but due to the
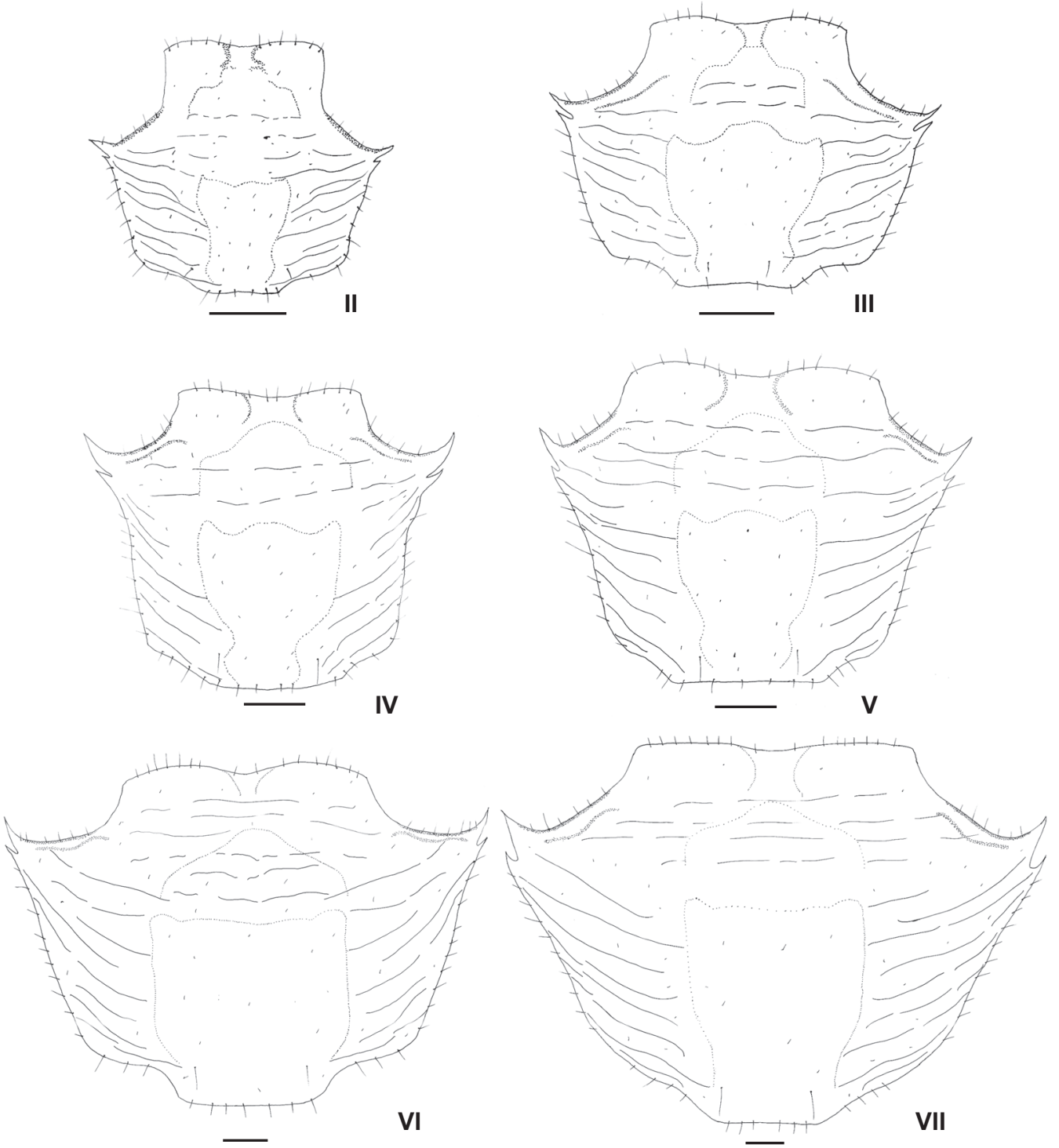

Figure 30. Pachygrapsus gracilis, juvenile instars. Carapace from juvenile instar II to VII. Scale bars: Juvenile instars II, IV-V = $0.7 \mathrm{~mm}$; Juvenile instars III $=0.6 \mathrm{~mm}$; Juvenile instar VI-VII $=0.5 \mathrm{~mm}$. 
fact that the illustrations were made from exuviae, the pleopods in juvenile II were damaged and they were not illustrated. Males: pleopods were not detected.

Juvenile III. Females: genital openings already present (Fig. 31); endopod of the four pairs of pleopods lacking setae; endopod 2-segmented; exopod unsegmented (Fig. 32). Males: genital opening already visible; showing only one pair of pleopod, biramous and rudimentary, lacking setae; in the males the second pair of pleopods is absent (Fig. 33).

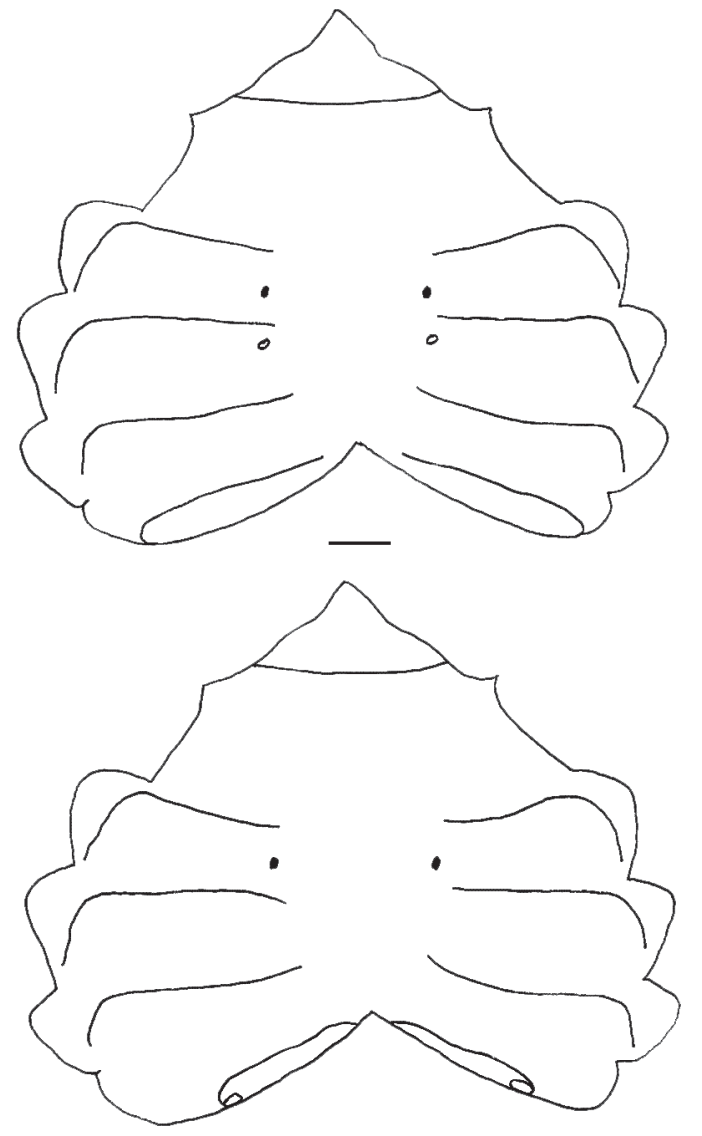

Figure 31. Pachygrapsus gracilis, genital openings of males and females in the juvenile instar III. Scale bar: $0.6 \mathrm{~mm}$.

Juvenile IV. Females: pleopods larger than in juvenile III; endopods 2-segmented, endopod of the second pair of pleopods with 3, 1 simple setae on distal and proximal segments, respectively, endopods of the third pair with one simple setae on each segment, endopods of the fourth pair lacking setae and endopod of the fifth pair with 2, 0 simple setae on distal and proximal segments, respectively; exopods unsegmented, exopod of the thrid pair of pleopods with two simple setae (Fig. 32). Males: pleopod larger than in the previous instar, lack-
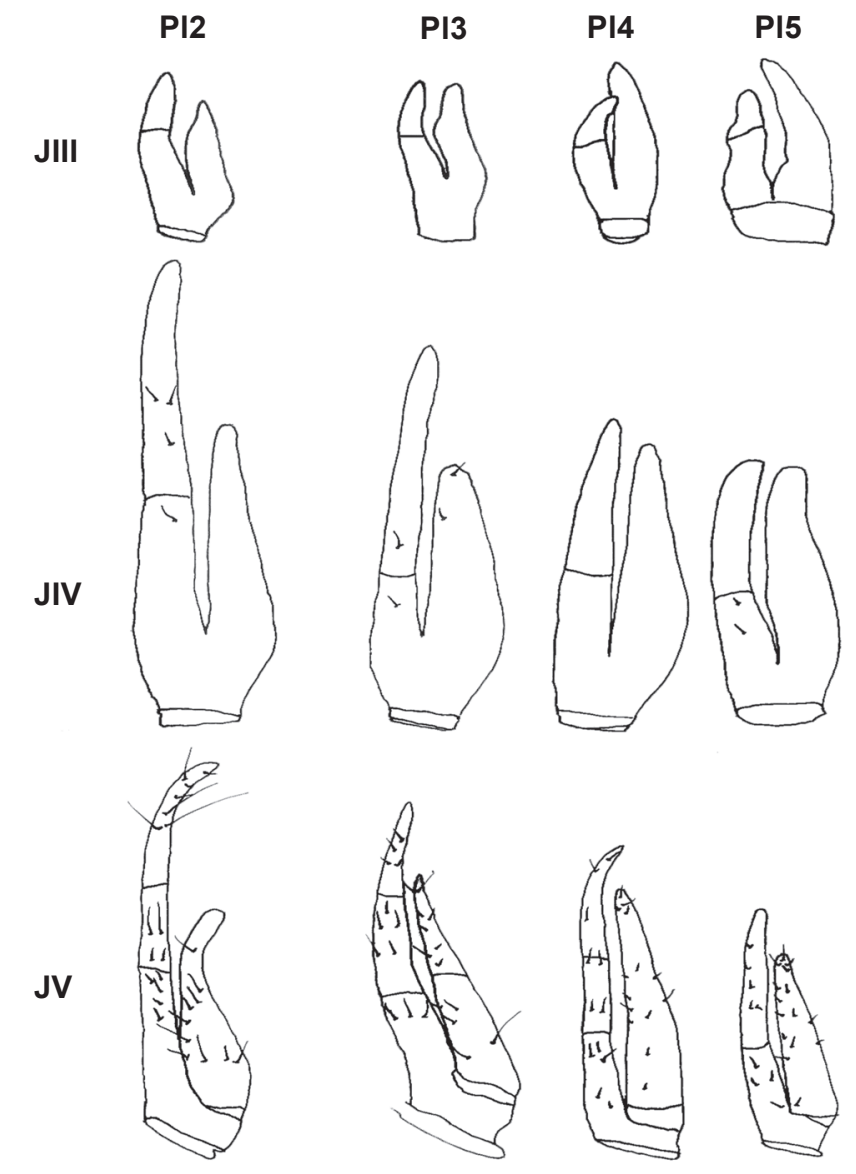

JVI
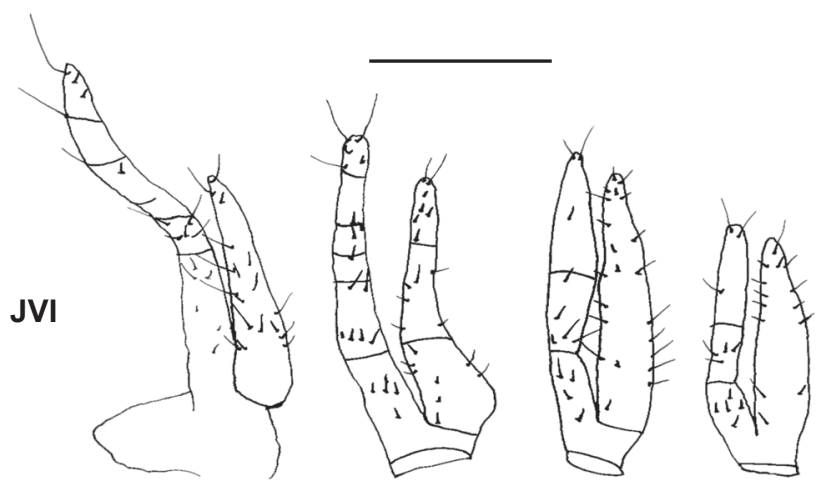

Figure 32. Pachygrapsus gracilis, juvenile instars. Female pleopods (PI2-PI5) from juvenile instar III to VI. Scale bar: JIII-JIV = $0.01 \mathrm{~mm}$; $J \mathrm{~V}-\mathrm{JVI}=0.02 \mathrm{~mm}$.

ing setae. The second pair of pleopods weren't detected in any juvenile instar (Fig. 33).

Juvenile V. Females: second, third, and fourth pairs of pleopods with endopod 3-segmented showing 7, 4, 5 simple setae on second pair, 4, 5, 3 on third pair and 3, 4, 5 on fourth pair; endopod of the fifth pair 2-segmented with 5, 4 simple 
setae; exopod of the second, fourth and fifth pairs unsegmented with 10, 14, 15 simple setae; exopod of the third pair 2-segmented with 8, 5 simple setae on proximal and distal segments, respectively (Fig. 32). Males: pleopods entirely developed. Endopod larger than exopod with a small distal groove rounded by numerous setae and with a longitudinal groove; exopod rudimentary (Fig. 33).

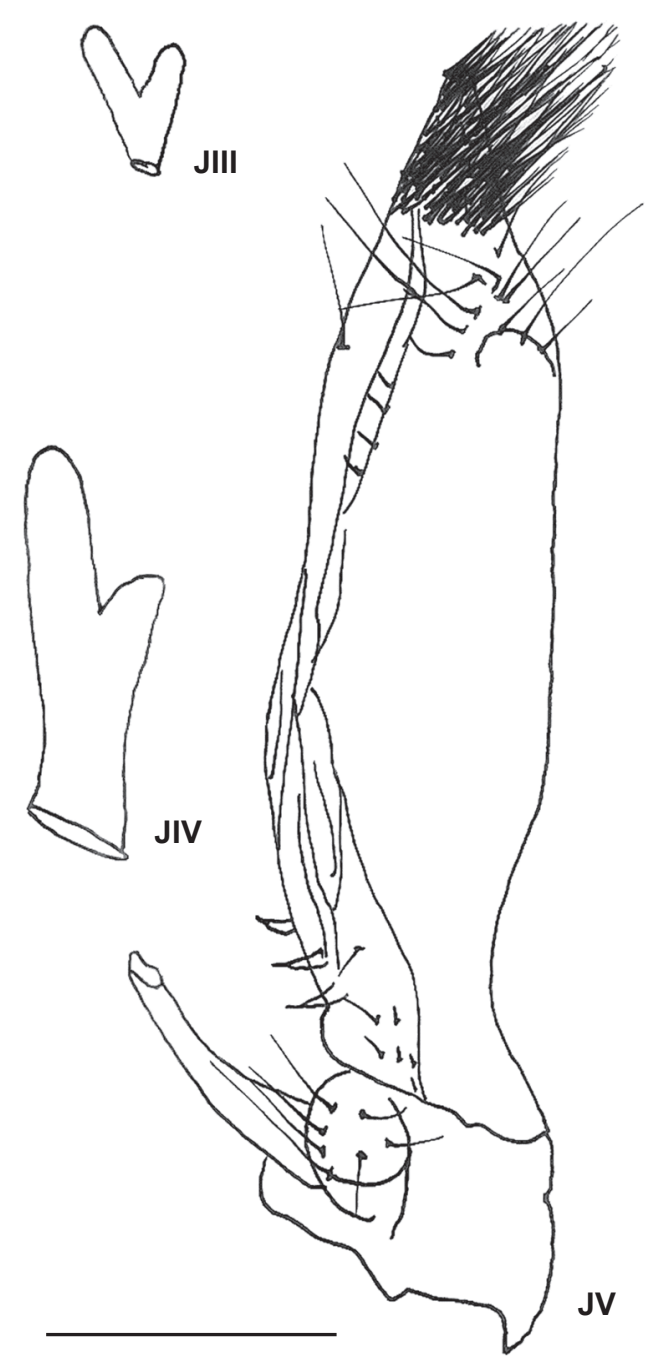

Figures 33. Pachygrapsus gracilis, juvenile instars. Male pleopod (PI1) from juvenile III to V. Scale bar: JIII-JIV $=0.01 \mathrm{~mm}$; JV $=0.02 \mathrm{~mm}$.

Juvenile VI. Females: pleopods fully developed; endopod of the second pair of pleopods 5-segmented with 4, 1, 1, 5, 6 simple setae; endopod of the third pair 6-segmented with 5, 1 $2,1,6,5$ simple setae, respective; endopod of the fourth and fifth pair 3-segmented with 3, 5, 4 and 3, 4, 5 simple setae, respectively; exopod of the second, fourth and fifth pair of pleopods unsegmented with $18,22,14$ simple setae; exopod of the third pair 3-segmented with 7, 6, 8 simple setae (Fig. 32). The sexual abdominal dimorphism could also be observed (Fig. 34). Males: similar to previous instar.

\section{DISCUSSION}

The analysis and comparisons with previous morphological studies available in the literature for the genus Pachygrapsus (Melo 1996, Poupin et al. 2005), clearly indicates that P. Gracilis, has some unique features, including gonopod not T-shaped, lateral margins convergent posteriorly and with tooth behind exorbital angle.

The number and type of setae in the appendages of already described species ( $P$. marmoratus, $P$. transversus and $P$. gracilis) are quite useful to differentiate among them, mainly the setae on the endopod of maxillule, maxilla and maxillipeds. Morphologically, all Pachygrapsus species studied have large eyes and a well-developed ocular peduncle. Beyond this, other similarities are found in the carapace characteristics, i.e, anterolateral region with lower expansion reaching orbital region and rostrum with a conspicuous medial depression. The carapace of the $P$. marmoratus and $P$. transversus are smooth and do not have a protuberance, whereas $P$. gracilis specimens from the Amazon and Mexico bear distinct lobes on the carapace.

Most of morphological differences are generally observed in the setal number and arrangement of: peduncle and endopod of the antennule, antenna, basal and coxal endites and endopod of the maxillule, maxilla endopod, first maxilliped exopod, fifth segment of the second maxilliped endopod, first segment of the third maxilliped exopod, pleopods and number of long setae on p5 (Tab. I).

The carapaces of $P$. marmoratus (Guerao et al. 1997) is larger $(\mathrm{CW}=2.10-2.30 \mathrm{~mm}, \mathrm{CL}=3.00-3.20 \mathrm{~mm})$, and $P$. transversus (Flores et al. 1998) (CW $=1.90 \mathrm{~mm}, \mathrm{CL}=2.80 \mathrm{~mm}$ ) megalopa are larger in average than those of our species. The Mexican specimens of $P$. gracilis (Chárazo-Olvera \& Rocha-Ramírez 2007) are larger than the Amazonian specimens. The carapace width of specimens from the Amazon was $1.39 \pm 0.04 \mathrm{~mm}$ and the carapace length was $1.97 \pm 0.04 \mathrm{~mm}$, while in Mexican specimens the carapace length and width were $2.20 \pm 0.02 \mathrm{~mm}$ and $1.57 \pm 0.04 \mathrm{~mm}$, respectively. However, many similarities were found between Mexican and Amazonian megalopae (see Tab. I).

The most notable difference found in the morphology of the two populations being compared was the presence of three distinct elongated setae, or feelers, on the fifth pair of the pereiopods, and the absence of those in the Mexican population. The other two species of the genus, $P$. marmoratus e $P$. transversus also have these feelers.

Other differences found between specimens from Mexico and the Amazon region of Brazil were as follows: setal number on antennule peduncle and endopod: Amazonian P. gracilis had 

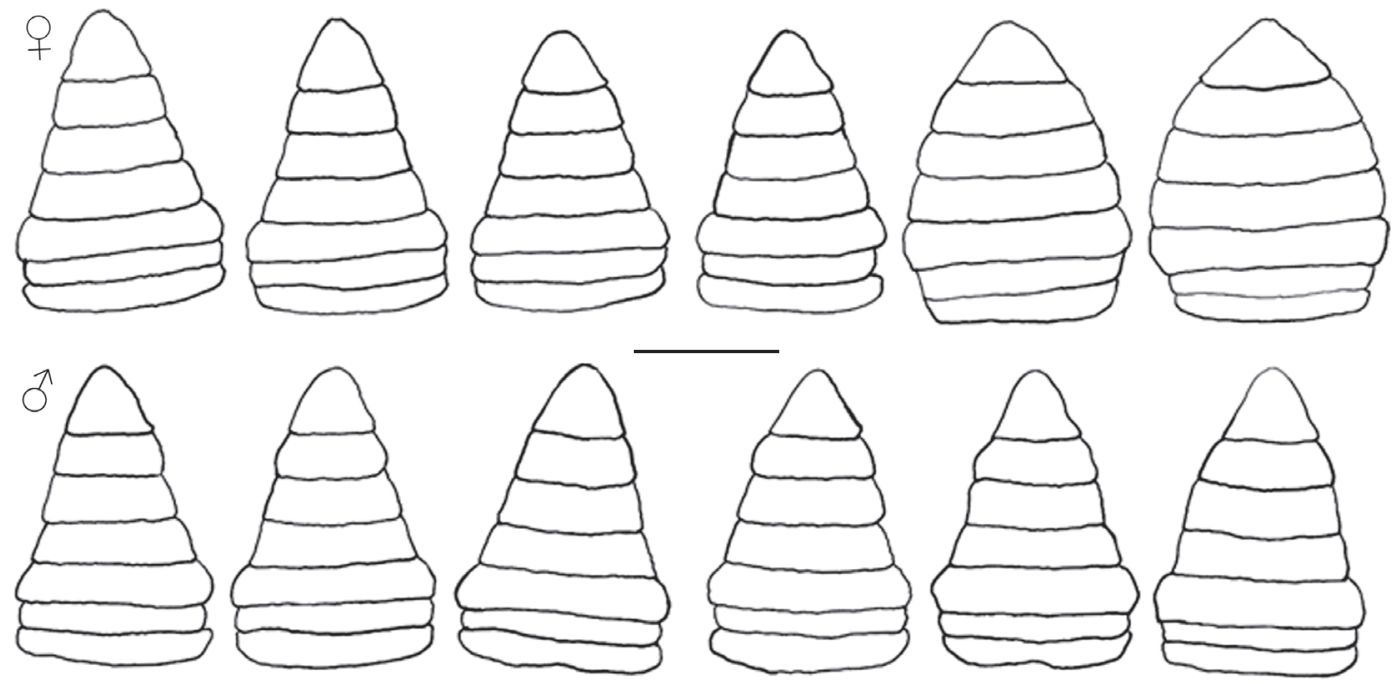

Figures 34. Pachygrapsus gracilis, male and female abdomen from juvenile instar II to VII. Scale bar: Females $-\mathrm{JII}=0.8 \mathrm{~mm} ; \mathrm{JII}=1.0$ $\mathrm{mm} ;:$ JIV = $1.2 \mathrm{~mm} ; \mathrm{JV}=1.5 \mathrm{~mm} ; \mathrm{JVI}=2.2 \mathrm{~mm} ; \mathrm{JVII}=2.0 \mathrm{~mm}$. Males $-\mathrm{JII}=0.8 \mathrm{~mm} ;: \mathrm{JII}=1.0 \mathrm{~mm} ;: \mathrm{JV}=1.1 \mathrm{~mm} ; \mathrm{JV}=1.4 \mathrm{~mm} ; \mathrm{JVI}=$ $2.1 \mathrm{~mm} ; \mathrm{JVII}=2.2 \mathrm{~mm}$.

a total of 11 setae on the peduncle and three distal setae on the endopod, while Mexican P. gracilis had only four setae on the peduncle and four distal setae on the endopod. Other important distinctions were also observed between Amazonian and Mexican species (see Tab. II). The morphological variations found within $P$. gracilis (Tab. II) when our data is compared with previous studies may be due to mistakes or omissions in other contributions, or variations between crab populations.

Few studies are available in the literature giving detailed description of the juvenile morphology. For instance, for $P$. marmoratus, only some structures of the juvenile instar I were observed by GUERAO et al. (1997). On the other hand, a comprehensive study, giving a detailed morphological description, was conducted on $P$. transversus from megalopa to the seven juvenile instar (Flokes et al. 1998).

The morphology of the juvenile instar I of $P$. gracilis is very similar to the morphology of the adult. The number of setae and their distribution pattern on the cephalic appendages and maxillipeds are typical for adult crabs, as also found by FLoREs et al. (1998) for $P$. transversus. In this juvenile, the two anterolateral teeth of the carapace are already visible in $P$. gracilis. In P. transversus, the anterolateral tooth is present only in the juvenile instar II. In P. marmoratus, by contrast, the three anterolateral teeth which can be observed in the adult, are already differentiated in the juvenile instar I. This suggests that the anterolateral teeth can be used to differentiate the juvenile I of congenerics. Other similarities and differences found between the species studied are shown on table II.

Similarities in the morphological characteristics and development of pleopods of juvenile males were observed in $P$. gracilis and Pyromaia tuberculata (Lockington, 1877) (FLoRes et al. 2002). In both species, only one pair of pleopods is present during the entire juvenile development. However, in P. transversus, as well as in Sesarma rectum Randall, 1840 (Fransozo 1987), Eriphia gonagra (J.C. Fabricius, 1781) (Fransozo \& Negreiros-Fransozo 1987), Eurypanopeus abbreviatus (Stimpson, 1860) (Fransozo \& Negreiros-Fransozo 1987) and Eurytium limosum (Say, 1818) (Guimarães \& Negreiros-Fransozo 2005), the pleopods show a varied pattern of development in which the juvenile may present one or two pairs of pleopods.

Differences are observed in the first appearance of the genital orifice of $P$. gracilis, $P$. transversus and $P$. tuberculata (FLORES et al. 2002). In males and females, the genital orifice arises in juvenile instars III, II and IV, respectively. Unfortunately, no comparisons could be made with other species because the authors did not mention details on the sexual dimorphism in these stages.

Studies on morphological descriptions of Pachygrapsus and other brachyuran species are very scarce, although they have been shown to be of great importance for systematic and diagnosis of species at different life stages. Thus, more studies on this topic should be made to contribute to the knowledge of the species biology and growth process.

When juvenile growths are compared, the pattern observed in $P$. gracilis juveniles is more similar to that of other cultured decapods. Growth patterns ascertained under culture conditions should be interpreted with caution because laboratory conditions and the natural environment are different. Environmental factors not present in controlled conditions, may affect the juvenile growth rate. In such case, the molt increment of specimens reared in the laboratory may be equivalent, and probably smaller than those in the field (HARTNOLL 1982). 
Table I. Morphological comparisons among megalopa stage of some Pachygrapsus species. (s) Setae, (a) aesthetascs, (es) elongated setae.

\begin{tabular}{|c|c|c|c|c|}
\hline & \multicolumn{2}{|r|}{ P. gracilis } & \multirow{2}{*}{$\frac{\text { P. transversus }}{\text { FLoREs et al. (1998) }}$} & \multirow{2}{*}{$\frac{\text { P. marmoratus }}{\text { GueRAo et al. (1997) }}$} \\
\hline & Present study & $\begin{array}{c}\text { Chárazo-Olvera \& Rocha Ramírez } \\
(2007)\end{array}$ & & \\
\hline \multicolumn{5}{|l|}{ Carapace } \\
\hline Length (mm) & $1.97 \pm 0.04$ & $2.20 \pm 0.02$ & 2.80 & $3.00-3.20$ \\
\hline Width (mm) & $1.39 \pm 0.04$ & $1.57 \pm 0.04$ & 1.90 & $2.10-2.30$ \\
\hline \multicolumn{5}{|l|}{ Antennule } \\
\hline Peduncle & $3,5,2+1 \mathrm{~s}$ & $0,2,2 \mathrm{~s}$ & $3,4,0 \mathrm{~s}$ & $9,5,2 \mathrm{~s}$ \\
\hline Endopod & $2+1 s$ & $4 s$ & $4 s$ & $0,3+1 s$ \\
\hline Exopod & $0,8,4,4,0 a+0,0,2,0,1+3 s$ & $0,15,8,5 a+0,0,2,3 s$ & $0,12,10,3 a+0,0,2,2 s$ & $0,16-18,13,5 a+0,0,1-2,2 s$ \\
\hline \multicolumn{5}{|l|}{ Antenna } \\
\hline Peduncle & $0,1+1,2 \mathrm{~s}$ & $1,1 \mathrm{~s}$ & $2,2,2 \mathrm{~s}$ & $0,4,3 \mathrm{~s}$ \\
\hline Flagelum & $0,0,4,2,4,0,3,3 \mathrm{~s}$ & $0,0,2,0,5,0,3,3 \mathrm{~s}$ & $0,0,3,3,3,2,2,2 s$ & $0,0,4,2,4-5,0,3,4 \mathrm{~s}$ \\
\hline \multicolumn{5}{|l|}{ Maxillule } \\
\hline Endopod & Os & $2 \mathrm{~s}$ & Os & $2,3 \mathrm{~s}$ \\
\hline Basal endite & $11-12+10+4 s$ & $11+3+9+1+2 s$ & $8+8+8 s$ & $29+4 s$ \\
\hline Coxal endite & $7+3+9 s$ & $10+2 s$ & $9 \mathrm{~s}$ & $18-20 s$ \\
\hline \multicolumn{5}{|l|}{ Maxilla } \\
\hline Scaphognathite & $70-72+3-4 s$ & $81+3 s$ & $85 \mathrm{~s}$ & $79-82+4 s$ \\
\hline Endopod & $0 \mathrm{~s}$ & $2 \mathrm{~s}$ & $0 \mathrm{~s}$ & $4 \mathrm{~s}$ \\
\hline Basal endite & $8-9+1+1,9-12+1 s$ & $8,2+12 s$ & $12,10 \mathrm{~s}$ & $16-17+13 s$ \\
\hline Coxal endite & $5+9,2+4 s$ & $4+1+3,2+2 s$ & $3+2,10+1+6 s$ & $5+15 s$ \\
\hline \multicolumn{5}{|l|}{$1^{\text {st }}$ Maxilliped } \\
\hline Endopod & $2 \mathrm{~s}$ & $2 s$ & $2 \mathrm{~s}$ & $4 s$ \\
\hline Basal endite & $13+2 s$ & $4+4+13 s$ & $10+3 s$ & $17 \mathrm{~s}$ \\
\hline Coxal endite & $4+1+12 s$ & $12 \mathrm{~s}$ & $12+6 s$ & $20 \mathrm{~s}$ \\
\hline Exopod & $3,4 \mathrm{~s}$ & $0,4 \mathrm{~s}$ & $4,4 s$ & $3-5,0,4 s$ \\
\hline \multicolumn{5}{|l|}{$2^{\text {nd }}$ Maxilliped } \\
\hline Endopod & $0,1,1,6,11+4 s$ & $0,1,1,4+1,10 \mathrm{~s}$ & $1,1,4,13 \mathrm{~s}$ & $2,1,6-7,12 \mathrm{~s}$ \\
\hline Exopod & $2,5 \mathrm{~s}$ & $1,5 \mathrm{~s}$ & $2,4 \mathrm{~s}$ & $1+1-3,0,5 s$ \\
\hline \multicolumn{5}{|l|}{$3^{\text {rd }}$ Maxilliped } \\
\hline Endopod & $13+1,5+4,5,9,8-10 \mathrm{~s}$ & $10,4+3,4,9+5+1+3,9+2 s$ & $4+12+1,7+3,2+4,11,13+2 s$ & $21-23,12,9-10,19,13 \mathrm{~s}$ \\
\hline Exopod & $5,4 \mathrm{~s}$ & $0,4 \mathrm{~s}$ & $4,4 s$ & $5-7,5 s$ \\
\hline Pereiopods & 3es & Oes & 3es & 3es \\
\hline \multicolumn{5}{|l|}{ Pleopods } \\
\hline Endopod & $4,4,4,4 \mathrm{~s}$ & $4,4,4,4 \mathrm{~s}$ & $4,4,4,3 \mathrm{~s}$ & $5,5,5,4 \mathrm{~s}$ \\
\hline Exopod & $28,23,24,22 s$ & $21,27,27,26 s$ & $30-32,32-35,28-34,24-26 s$ & $27,30,28,25 s$ \\
\hline \multicolumn{5}{|l|}{ Uropod } \\
\hline Exopod & $3,15-16 s$ & $3,17 \mathrm{~s}$ & $21 \mathrm{~s}$ & $2,17 \mathrm{~s}$ \\
\hline
\end{tabular}


Table II. Morphological comparisons among juvenile I of some Pachygrapsus species. (s) Setae, (a ) aesthetascs, (sp) spine, (n) numerous setae, (ns) numerous setae in all segments.

\begin{tabular}{|c|c|c|c|}
\hline & P. gracilis (Present study) & P. transversus (Flores et al. 1998) & P. marmoratus (Guerao et al. 1997) \\
\hline \multicolumn{4}{|l|}{ Carapace } \\
\hline Length (mm) & $1.96 \pm 0.07$ & 2.30 & 2.80 \\
\hline Width (mm) & $2.20 \pm 0.13$ & 2.80 & $3.19-3.20$ \\
\hline \multicolumn{4}{|l|}{ Antennule } \\
\hline Peduncle & $\mathrm{n}, 1+4,4+1 \mathrm{~s}$ & $18+25,2,3 \mathrm{~s}$ & absent \\
\hline Endopod & $1,2,1+2 s$ & $3,2,3 \mathrm{~s}$ & absent \\
\hline Exopod & $0,10-12,11,3,0,0 a+0,2,2,1,3+1,2$ & $0,8,7,3,0,0 a+0,1,1,4,4,3 \mathrm{~s}$ & absent \\
\hline \multicolumn{4}{|l|}{ Antenna } \\
\hline Peduncle & $5+3,2+4,2 s$ & $7,6,3 \mathrm{~s}$ & absent \\
\hline Flagelum & $0,4,2,2,4,0,2,2 \mathrm{~s}$ & $3,2,4,3,4,1,1,3 \mathrm{~s}$ & absent \\
\hline \multicolumn{4}{|l|}{ Maxillule } \\
\hline Endopod & $2,2+2 s$ & $5,4+2 s$ & absent \\
\hline Basal endite & $15+1+13 s$ & $1+5+23+6$ & absent \\
\hline Coxal endite & $5+28-30 s$ & $8+14+7+5$ & absent \\
\hline \multicolumn{4}{|l|}{ Maxilla } \\
\hline Scaphognathite & $87-95+25 s$ & $120 \mathrm{~s}$ & absent \\
\hline Endopod & $1 \mathrm{~s}$ & Os & absent \\
\hline Basal endite & $14-15+3+3,11+8 s$ & $4+14-16,4+5+2 s$ & absent \\
\hline Coxal endite & $5,16+3 s$ & $9,7+5+10-13 s$ & absent \\
\hline \multicolumn{4}{|l|}{$1^{\text {st }}$ Maxilliped } \\
\hline Endopod & $12,12+9-13 s$ & $\mathrm{n}, 10+10 \mathrm{~s}$ & absent \\
\hline Basal endite & $\mathrm{n}$ & $\mathrm{n}$ & \\
\hline Coxal endite & $\mathrm{n}$ & $\mathrm{n}$ & \\
\hline Exopod & $10,4 \mathrm{~s}$ & $1+4,6 s$ & absent \\
\hline \multicolumn{4}{|l|}{$2^{\text {nd }}$ Maxilliped } \\
\hline Endopod & $4,6,5+5+6,5,5+3,7+15-17$ & $4,2,4+n, 4,7-9+7, n$ & absent \\
\hline Exopod & $12-13+11-13,4 s$ & $8+8-11+11,3+6 s$ & absent \\
\hline \multicolumn{4}{|l|}{$3^{\text {rd }}$ Maxilliped } \\
\hline Endopod & $38,20,20,18,18$ & $3+n, 5+6+8,11-13, n, n+2$ & $65,35,39,35,17 \mathrm{~s}$ \\
\hline Exopod & $18,5 s$ & $8+8+1,3+6 s$ & $+41,8 s$ \\
\hline
\end{tabular}

Increases in the duration of the intermolt period and in carapace size at each subsequent juvenile instar accompanied a decrease in molt size increment during juvenile rearing. The mean intermolting periods of $P$. gracilis juveniles were: $6.2 \pm$ $3.4,8.2 \pm 3.4,12.5 \pm 3.2,11.5 \pm 4.9,12.6 \pm 7.5,15 \pm 8,20.4 \pm 12$ days in juveniles I, II, III, IV, V, VI, and VII, respectively (Fig. 2). These results could be compared with other congeneric species. However, studies on juvenile growth are scarce, with only one study on this theme reported for a Brazilian species, $P$. transversus (Flores et al. 1998). Fortunately, the authors, as in the present study, described the early seven juvenile instars of $P$. transversus. The mean intermolt duration in each juvenile instar of $P$. transversus was recorded as $17.9 \pm 8,17.8 \pm 6.2,18.6 \pm$ $4.7,22.5 \pm 5.1,20.5 \pm 7.5,25.8 \pm 4.9,28$ days for juveniles I, II, III, IV, V; VI and VII, respectively. Such results are quite different from those found in the present study, in which intermolt values were considerably lower in all instars (Fig. 2).

A few more studies measuring carapace size in each juvenile instar have been conducted for other species of Pachygrapsus: P. marmoratus (GUERAO et al. 1997), and P. transversus (FLoREs et al. 
1998). The dimensions of carapace length of $P$. transversus (FLoRES et al. 1998) and $P$. gracilis (present study) were compared. The latter species has a shorter carapace in the first six instars and a longer carapace in the juvenile VII (Fig. 3). On the other hand, $P$. transversus, showed carapace length of $2.3 \pm 0.1 \mathrm{~mm}, 2.6 \pm 0.2$ $\mathrm{mm}, 3.0 \pm 0.2 \mathrm{~mm}, 3.5 \pm 0.3 \mathrm{~mm}, 4.1 \pm 0.5 \mathrm{~mm}, 4.6 \pm 0.5 \mathrm{~mm}$, $5.0 \pm 0.4 \mathrm{~mm}$ in juveniles I, II, III, IV, V, VI, and VII, respectively. In the Mediterranean species P. marmoratus (GuERAo et al. 1997), the largest carapace sizes of all studied species have been observed. In the 4 early instars of this crab, the carapace was 2.90, $3.20,4.20$, and $5.20 \mathrm{~mm}$ long for juveniles I, II, III and IV, respectively. Important information could be made, comparing $P$. gracilis (present study) with the Mexican P. gracilis but, unfortunately, the data was not presented by those authors. The carapace size in males and females of $P$. gracilis were compared in present study and no significant difference in size was observed (Fig. 4).

Pachygrapsus gracilis have also been demonstrated to be resilient, having a survival rate up $75 \%$. This result is considerably elevated when compared to Mexican populations which present a survival rate of approximately only 30\% (СHÁRAZOOlvera \& Rocha-Ramírez 2007). For P. transversus (Flores et al. 1998), 17 megalopae were collected and only 1 individual survived until juvenile instar VII.

The sexual dimorphism on the abdomen development has not been fully investigated (Flores et al. 1998, 2002). Such study would be very important because abdominal development is associated with the reproductive activity of males and females. Such analysis is commonly performed in studies on the relative growth of brachyurans. The positive allometric growth of the female abdomen has generally been associated with morphological requirements for reproduction in adults. Thus, large abdomens protect and incubate a larger number of eggs, increasing the reproductive potential of females (HARTNOLL 1974). The abdominal sexual dimorphism in $P$. gracilis and $P$. transversus developed in juvenile VI. Females develop a larger abdomen with respect to males this instar (Fig. 6).

\section{ACKNOWLEDGEMENTS}

The present study was supported by a scholarship from Coordenação de Aperfeiçoamento de Pessoal de Nível Superior.

\section{LITERATURE CITED}

Barutot, R.A.; R.R.R. Vieira \& P.J. Rieger. 2001. Desenvolvimento juvenil de Callinectes sapidus Rathbun, 1896 (Crustacea: Decapoda: Portunidae), em laboratório, a partir de megalopas coletadas no plâncton. Comunicações do Museu de Ciências e Tecnologia da PUCRS, Série Zoologia, 14 (1): 23-42.

Chárazo-Olvera, S. \& A. Rocha-Ramírez. 2007. Morphology of the Pachygrapsus gracilis (Saussure, 1858) megalopa (Brachyura, Grapsidae) reared in the laboratory. Crustaceana 80 (1): 1930.
Flores, A.A.V.; M.L. Negreiros-Fransozo \& A. Fransozo. 1998. The Megalopa and juvenile development of Pachygrapsus transversus (Gibbes, 1850) (Decapoda, Brachyura) compared with other Grapsid crabs. Crustaceana 71 (2): 197-222.

Flores, A.A.V.; Marques, F.P.L. \& Negreiros-Fransozo, M.L. 2002. Post larval stages and growth patterns of the spider crab Pyromaia tuberculata (Brachyura, Majidae) from laboratory-reared material. Journal of Crustacean Biology 22 (2): 314-327.

Fransozo, A. 1987. Desenvolvimento dos estágios juvenis de Sesarma (Holometopus) rectum Randall, 1840 (Decapoda, Grapsidae), obtidos em laboratório. Naturalia 12: 77-87.

Fransozo, A. \& M.L. Negreiros-Fransozo. 1987. Morfologia dos primeiros estágios juvenis de Eriphia gonagra (Fabricius, 1781) e Eurypanopeus abreviatus (Stimpson, 1860) (Crustacea, Decapoda, Xanthidae), obtidos em laboratório. Papéis Avulsos de Zoologia 36 (22): 257-277.

Garm, A. 2004. Revising the definition of the crustacean seta and setal classification systems based on examinations of the mouthpart setae of seven species decapods. Zoological Journal of the Linnean Society 142: 233-252.

Guerao, G.; P. Abelló \& J.A. Cuesta. 1997. Morphology of the megalopa and first crab stage of the mediolittoral crab Pachygrapsus marmoratus (Brachyura, Grapsidae, Grapsinae). Zoosystema 19 (2-3): 437-447.

Guimarães, F.J. \& M.L. Negreiros-Fransozo. 2005. Juvenile development and growth patterns in the mud crab Eurytium limosum (Say, 1818) (Decapoda, Brachyura, Xanthidae) under laboratory conditions. Journal of Natural History 39 (23): 2145-2161.

HARTNOLL, R.G. 1974. Variation in growth pattern between some secondary sexual characters in crabs (Decapoda, Brachyura). Crustaceana 27: 151-156.

Hartnoll, R.G. 1982. Growth, p. 111-196. In: L.G. Abele (Ed). The Biology of Crustacea: Embryology, Morphology and Genetics. New York, Academic Press, vol. 2, 440p.

Melo, G.A.S. 1996. Manual de identificação dos brachyura (caranguejos e siris) do litoral brasileiro. São Paulo, Museu de Zoologia, Universidade de São Paulo, Editora Plêiade, 604p.

Pohle, G. \& M. Telford. 1981. Morphology and classification of decapod crustacean larval setae: a scanning electron microscope study of Dissodactylus crinitichelis Moreira, 1901 (Brachyura: Pinnotheridae). Bulletin of Marine Science 31 (3): 736-752.

Poupin, J.; P.J.F Davie \& J.C. Cexus. 2005. A revision of the genus Pachygrapsus Randall, 1840 (Crustacea: Decapoda: Brachyura, Grapsidae), with special reference to the Southwest Pacific species. Zootaxa 1015: 1-66.

Rodriguez, G. 1980. Los crustaceos decapodos de Venezuela. Caracas, Instituto Venezolano de Investigaciones Científicas, 494p.

Submitted: 08.V.2010; Accepted: 28.I.2011.

Editorial responsibility: Marcos D.S. Tavares 